\title{
Wet-Side Breath-Enhanced Jet Nebulization: Controlling Drug Delivery During Mechanical Ventilation
}

\author{
Ann D Cuccia, Sunya Ashraf, Michael McPeck, Joshua Samuel, and Gerald C Smaldone
}

\begin{abstract}
BACKGROUND: The present study tested a novel nebulizer and circuit that use breath enhancement and breath actuation to minimize ventilator influences. The unique circuit design incorporates "wetside" jet nebulization (the nebulizer connected to the humidifier outlet port) to prevent unpredictable aerosol losses with active humidification. The system was studied using several ventilator brands over a wide range of settings, with and without humidification. METHODS: During treatment, a 2-position valve directed all ventilator flow to the nebulizer, providing breath enhancement during inspiration. Aerosol was generated by air $50 \mathrm{psi} 3.5 \mathrm{~L} / \mathrm{m}$ triggered during inspiration by a pressure-sensitive circuit. Particles were captured on an inhaled mass filter. Testing was performed by using active humidification or bypassable valved heat and moisture exchanger (HME) over a range of breathing patterns, ventilator modes, and bias flows $(0.5-5.0 \mathrm{~L} / \mathrm{m})$. The nebulizer was charged with $6 \mathrm{~mL}$ of radiolabeled saline solution. Mass balance was performed by using a gamma camera. Tidal volume was monitored by ventilator volume (exhaled $V_{T}$ ) and test lung volume. The Mann-Whitney test was used. RESULTS: A total of $6 \mathrm{~mL}$ was nebulized within $1 \mathrm{~h}$. Inhaled mass (\% neb charge): mean \pm SD (all data) $31.1 \% \pm 6.45$; no. $=83$. Small significant differences were seen with humidification for all modes (humidified 36.1\% \pm 5.60 , no. $=26$; bypassable valved HME $28.8 \% \pm 5.51$, no. $=57$ $[P<.001])$, continuous mandatory ventilation modes $[P<.001]$, and pressure support airway pressure release ventilation modes $[P<.001]$. Mass median aerodynamic diameter ranged from 1.04 to 1.34 $\mu \mathrm{m}$. The $V_{\mathrm{T}}$ was unaffected (exhaled $V_{\mathrm{T}} \mathbf{- 5 . 0} \pm \mathbf{1 2 . 9} \mathrm{mL} ; P=.75$ ) and test lung (test lung volume $25 \pm 14.5 \mathrm{~mL} ; P=.13)$. Bias flow and PEEP had no effect. CONCLUSIONS: Breath enhancement with breath actuation provided a predictable dose at any ventilator setting or type of humidification. Preservation of drug delivery during active humidification is a new finding, compared with previous studies. The use of wall gases and stand alone breath actuation standardizes conditions that drive the nebulizer independent of ventilator design. Wet-side nebulizer placement at the humidifier outlet allows delivery without introducing aerosol into the humidification chamber. Key words: aerosols; nebulizers and vaporizers; administration; inhalation; ventilators; mechanical; humidifiers; drug delivery; bias flow. [Respir Care 2020;65(8):1077-1089. (C) 2020 Daedalus Enterprises]
\end{abstract}

\section{Introduction}

Aerosol delivery to patients who are intubated and on mechanical ventilation is more complex than during

\footnotetext{
Ms Cuccia is affiliated with the Stony Brook University Respiratory Care Program, Stony Brook, New York. Dr Ashraf, Mr McPeck, Dr Samuel, and Dr Smaldone are affiliated with the Stony Brook University Medical Center, Pulmonary, Critical Care and Sleep Medicine, Stony Brook, New York.

The study location was the Aerosol Laboratory, Division of Pulmonary, Critical Care and Sleep Medicine, Stony Brook University Medical Center, Stony Brook, New York.
}

spontaneous breathing because the mechanical ventilator is an integral part of the aerosol delivery system. Ventilator function is not linked to aerosol delivery and can confound dose delivery to the patient. Previous studies identified important factors that individually, and in combination, impact aerosol delivery, including the following: position

\footnotetext{
The study was supported in part by InspiRx, The State University of New York at Stony Brook holds patents in the fields of nebulizer development and antibiotic delivery, which have been licensed to InspiRx.

Dr Smaldone and Ms Cuccia disclose relationships with InspiRx. The other authors have disclosed no conflicts of interest.
} 
in the ventilator circuit, ${ }^{1-4}$ humidification, ${ }^{2,5-8}$ duty cycle, ${ }^{6,79}$ bias flow, ${ }^{1,5}$ nebulizer technology, ${ }^{1,2,6,7,10,11}$ nebulizer driving pressure and flow, ${ }^{5,12}$ internal ventilator valves, ${ }^{13}$ device reliability, ${ }^{14}$ fill volume, ${ }^{4,15}$ and treatment time. ${ }^{6,7}$ Output data from commercially available devices published in the literature, ${ }^{1,2,5,8,16-21}$ demonstrate that, with current technologies, dose delivery varies widely based on nebulizer technology and ventilator setting are summarized in Figure 1.

\section{See the Related Editorial on Page 1223}

The present article describes a new jet nebulizer-ventilator circuit combination (i-AIRE, InspiRx, Somerset, New Jersey) designed to mitigate the problems described above and deliver a predictable dose to the patient who is intubated and on mechanical ventilation. The device incorporates the concept of breath enhancement into the ventilator circuit. The nebulizer is powered by wall gases at $50 \mathrm{psi}$ at a relatively low flow of $3.5 \mathrm{~L} / \mathrm{min}$. The new nebulizer-circuit design directs all inspiratory ventilator flow directly through the top of the nebulizer during active nebulization. A Venturi effect within the nebulizer enhances aerosol generation only during inspiration (Fig. 2). Breath enhancement, therefore, should increase nebulizer output, reducing both treatment time and the influence of expiratory phenomena on aerosol losses, for example, duty cycle.

Combined with a pressure-controlled independent breathactuated circuit, providing wall gases to the nebulizer only during inspiration (breath actuation), dose delivery to patients who are intubated may be improved. Active humidification can result in unpredictable losses of generated aerosol in ventilator tubing and, depending on nebulizer location, in the humidifier. ${ }^{1}$ Clinical studies have avoided humidification entirely to prevent these effects. ${ }^{5,22-24}$ Modern use of dry-side humidification may lead to humidifier contamination. To prevent humidifier losses and potential contamination, we placed our nebulizer on the "wet" side of the humidifier (humidifier outlet). To test this nebulizer-system design, the effects on aerosol delivery by

Dr Ashraf presented a version of this paper at the 22nd International Society for Aerosols in Medicine Congress, held May 25-29, 2019 in Montreux, Switzerland; by Ms Cuccia at the Stony Brook University 13th Annual Women in Medicine Conference, held March 6, 2019 in Stony Brook, New York; and by Ms Cuccia at the AARC Congress 2018, held December 4-7, 2018 in Las Vegas, Nevada.

Correspondence: Ann D Cuccia MPH RRT, Stony Brook University Respiratory Care Program, School of Health Technology and Management, HSC Level 2, Room 412, Stony Brook, NY 11794-8203. E-mail: ann.cuccia@stonybrook.edu.

DOI: $10.4187 /$ respcare. 07343

\section{QUICK LOOK}

\section{Current knowledge}

Drug delivery to the patient who is intubated and on mechanical ventilation is uncontrolled, with published studies reporting values that range from $2.7 \%$ to $41 \%$ of the nebulizer dose. This variability may affect the results of clinical studies for drugs that cannot be assessed at the bedside, for example, antibiotics. Important variables include nebulizer type, duty cycle, bias flow, nebulizer position, and methods of humidification.

\section{What this paper contributes to our knowledge}

The i-AIRE system with breath-enhancement and stand-alone breath-actuation provided predictable drug delivery during invasive ventilation, independent of the ventilator type, across a wide range of commonly used settings, with and without humidification. Wet-side nebulizer placement at the humidifier outlet avoided humidifier effects on aerosol delivery and contamination of the humidifier.

using 3 different ventilators, a wide range of settings, modes, and bias flows with and without humidification were measured. Particle distribution was measured after the endotracheal tube. Mass balance was performed to test assumptions of nebulizer function and effects of humidification.

\section{Methods}

\section{Nebulizer}

Jet nebulizers have a nebulizing chamber or reservoir that contains liquid medication; a jet of pressurized gas is directed through a narrow orifice, which results in a reduction in pressure and medication being drawn up through the capillary tube from the nebulizer reservoir into the gas stream. Baffles placed in the aerosol stream act to produce smaller particles and remove larger particles, returning them to the reservoir. Breath-enhanced jet nebulizers that are currently used in spontaneously breathing patients are designed to generate more aerosol during inspiration ${ }^{25}$ by entraining the patient's inspiratory flow through the top of the nebulizer into the nebulizing chamber, increasing nebulizer output during inspiration relative to expiration. ${ }^{26}$ The i-AIRE system jet nebulizer (Fig. 3) functions in a similar manner.

The i-AIRE system is designed to accept all inspiratory flow going from the ventilator to the patient. This flowenhanced aerosol effect operates only during inspiration (breath-enhanced nebulization). To generate aerosol, the nebulizer requires wall air or oxygen using a standard flow 


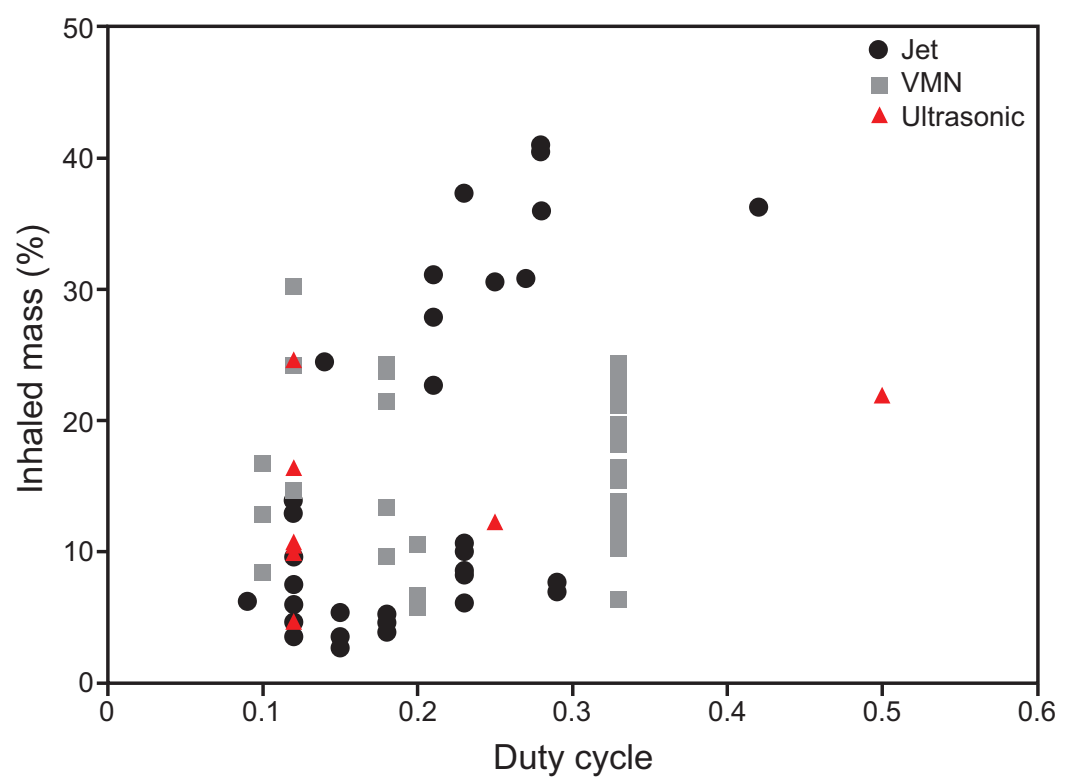

Fig. 1. Inhaled mass data from current nebulizer technologies reported in the literature. Inhaled mass as percentage of nebulizer charge versus duty cycle (inspiratory time/total cycle time $\left[T_{1} / T_{\text {tot }}\right]$ ).

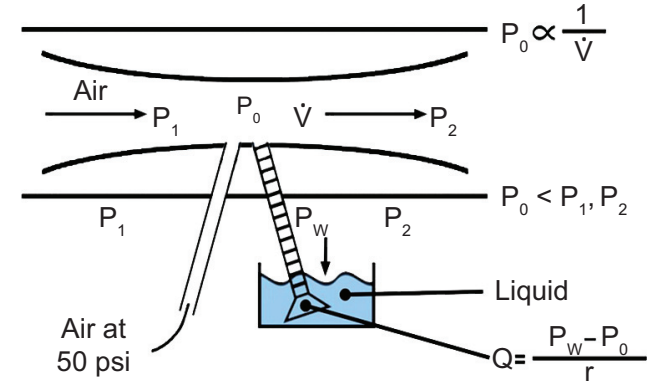

Fig. 2. Breath enhancement. Venturi effect created by added flow through the top of nebulizer causes a further decrease in pressure across the nebulizer chimney $\left(P_{0}\right)$ inversely proportional to local air flow $(\dot{V})$. The drop in pressure augments the rate at which liquid is drawn through the capillary tube $(Q)$, which results in an increase in rate of aerosol formation and nebulizer output during inspiration.

meter at $3.5 \mathrm{~L} / \mathrm{min}, 50 \mathrm{psi}$, is controlled by a pressure-actuated solenoid, activated only during inspiration (breathactuated nebulization). The $3.5 \mathrm{~L} / \mathrm{m}$ flow is delivered to the nebulizer gas inlet nipple and is controlled by the solenoid, which actively opens and delivers the $3.5 \mathrm{~L} / \mathrm{m}$ flow during a defined percentage of inspiration, and actively closes and ceases flow to the nebulizer during the expiratory phase. At the same time, during inspiration, all inspiratory gas flow from the ventilator is directed through the nebulizer (breath enhancement) (Fig. 2); this added flow through the top of the nebulizer lowers the local pressure in the nebulizer, causing a further decrease in pressure, which augments the rate at which liquid is drawn through the capillary tube and increasing the rate of aerosol formation and nebulizer output.
The i-AIRE jet nebulizer was filled (nebulizer charge) with $6 \mathrm{~mL}$ of normal saline solution mixed with technetium-99m and connected either to the wet side (humidifier outlet) of the humidifier or to the inspiratory outlet of the ventilator via a unique 2-way breathactuated-breath-enhanced valved circuit (Figs. 4 and 5). The 6-mL nebulizer charge was chosen to assess delivery of volumes consistent with antibiotic solutions. The run time during early experiments varied between 30 and $60 \mathrm{~min}$, depending on the duty cycle and the presence or absence of humidity (estimated, from the time that the 2-position valve was turned to engage breath enhancement to the point of cessation of aerosol production determined by visual inspection). Based on these observations, run time was standardized to $60 \mathrm{~min}$ for all the experiments defined from the time that the 2postion valve was turned to engage breath enhancement and ended at $60 \mathrm{~min}$ (measured by a stopwatch).

\section{Solenoid}

The pressure-activated solenoid (ARO Solenoid M182SD-012, Ingersoll-Rand, Bryan, Ohio) actively opened and actively closed via dual electromagnetic controls triggered by an electronic circuit. This was accomplished by using an Arduino controller board to sense pressure and control the solenoid. First, for several breaths, the circuit assessed the average inspiratory time $\left(\mathrm{T}_{\mathrm{I}}\right)$. Then, once the circuit sensed the increase in airway pressure during inspiration, the 


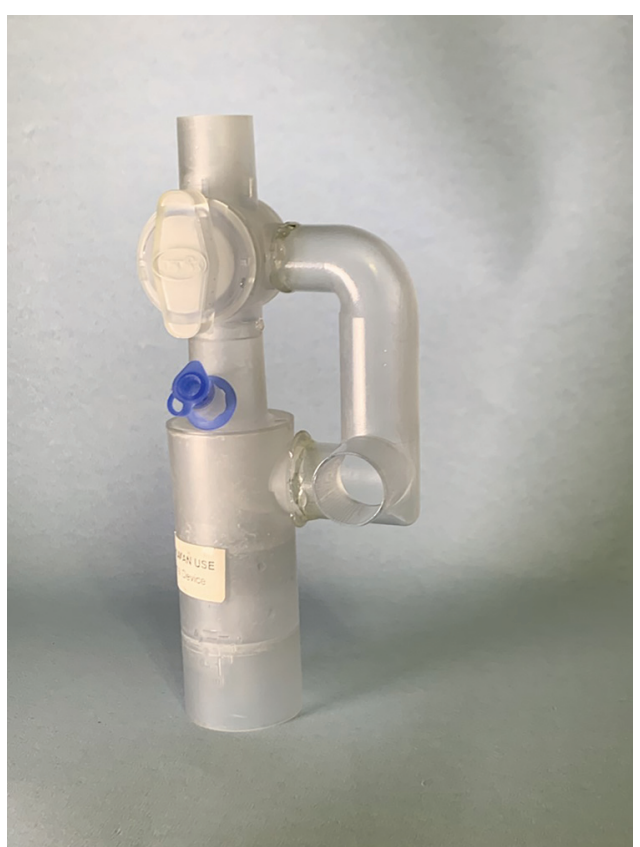

Fig. 3. The i-AIRE nebulizer with 2-position valve.

solenoid opened in $\sim 20 \mathrm{~ms}$ and remained open until $\sim 75 \%$ of inspiration was completed, and the valve actively closed.

\section{The Circuit}

Our model is outlined in Figures 4 and 5. Breath enhancement required that, during aerosol therapy, all ventilator inspiratory flow be directed to the nebulizer. During active humidification (Fig. 4), the system was positioned on the wet side (humidifier outlet) of the humidifier (MR850, Fisher Paykel, Auckland, New Zealand; or ConchaTherm Neptune, Teleflex Medical, Teleflex Medical, Morrisville, North Carolina). During a treatment, the 2-position valve was turned to the nebulizer and the breath-actuation circuit engaged. Inspiratory gas passed through the humidifier in the usual manner and after exiting the humidifier, was diverted through the top of the nebulizer. After treatment was completed (Fig. 4 , insert), the breath-actuating circuit was turned off and the 2-position valve turned, which bypassed the nebulizer and directed flow to the conventional circuit.

During passive humidification (Fig. 5), the i-AIRE system was positioned at the inspiratory outlet of the ventilator. During aerosol delivery, the bypassable valved heat and moisture exchanger (HME) was turned to the aerosol position, and the air flow was diverted in the same manner by using the 2-position valve. After treatment was completed (Fig. 5, insert), flow was redirected to the conventional circuit by turning the 2-position valve, and the HME turned to the HME position. Ventilatory parameters were measured during nebulization with an
ASL 5000 test lung (Ingmar Medical, Pittsburgh, Pennsylvania). Positioning the nebulizer on the wet side (humidifier outlet) allows aerosol to be delivered through the circuit without coming in contact with the humidifier chamber. To avoid potential effects of nebulized cold aerosol and wall gas on humidification, the temperature probe of the humidifier was relocated from the standard location on the proximal end of the conventional inspiratory line to the point where the 2-position valve was placed on the humidifier (Fig. 4).

Three test ventilators were used in this study: Avea (Vyaire Medical, Mettawa, Illinois), Dräger V500 (Dräger Medical, Lubeck, Germany), and Servo-i (Maquet, Getinge, Solna, Sweden). Each ventilator was connected via a standard $22-\mathrm{mm}$ ventilator circuit, heated wire circuits were used for experiments that used active humidification (Evaqua, Fisher Paykel; or Hudson RCI ISOGARD, Teleflex Medical). Heated humidification experiments were tested by using either the MR850 humidifier (Fisher Paykel) or ConchaTherm Neptune humidifier (Teleflex Medical) set at $37^{\circ} \mathrm{C}$. For the HME configuration, the circuit contained a HME (Curaplex ClearPath HME, Tri-anim, Dublin, Ohio).

During active humidification, before aerosolization, the heated wire circuit was heated and humidified for $\sim 20 \mathrm{~min}$ to reach a stable $37^{\circ} \mathrm{C}$. To complete the circuit, a closed suction system (Halyard Health, Alpharetta, Georgia) and a 7.5-mm endotracheal tube (Rusch, Teleflex, Medical) were connected to an ASL 5000 test lung. An inhaled mass (IM) filter (Pari, Starnberg, Germany) placed in the circuit distal to the endotracheal tube measured the aerosol particles that would be inhaled by a patient (IM) under similar conditions. A similar filter was placed in the expiratory line for mass balance measurements.

Ventilator settings are listed in Tables 1-6. Ventilator modes were chosen to encompass relevant clinical settings, including controlled mechanical ventilation, pressure support, and patient-triggered breaths. Most experiments were conducted at a bias flow of $2.0 \mathrm{~L} / \mathrm{min}$. The ASL 5000 test lung served 2 roles, (1) it monitored ventilatory parameters during aerosol delivery, and (2) it served to trigger the ventilator during assisted and pressure-supported modes of ventilation. Each mode was tested by using all 3 ventilator brands at varying airway pressures, tidal volumes $\left(\mathrm{V}_{\mathrm{T}}\right)$, frequencies, $\mathrm{T}_{\mathrm{I}}$ (duty cycle), and a PEEP of $5 \mathrm{~cm}$ $\mathrm{H}_{2} \mathrm{O}$ at $21 \%$ oxygen with $2.0 \mathrm{~L} / \mathrm{m}$ bias flow during HME or active humidification. In a separate series of experiments, the effect of PEEP was tested by using 4 ventilator settings, and bias flow was tested with HME by using 2 ventilator settings.

\section{Particle Distribution}

In another series of experiments, particles were sampled via a cascade impactor $(2 \mathrm{~L} / \mathrm{min}$ flow, Marple 8-stage impactor, 


\section{Wet-Side Breath-Enhanced Jet Nebulization}

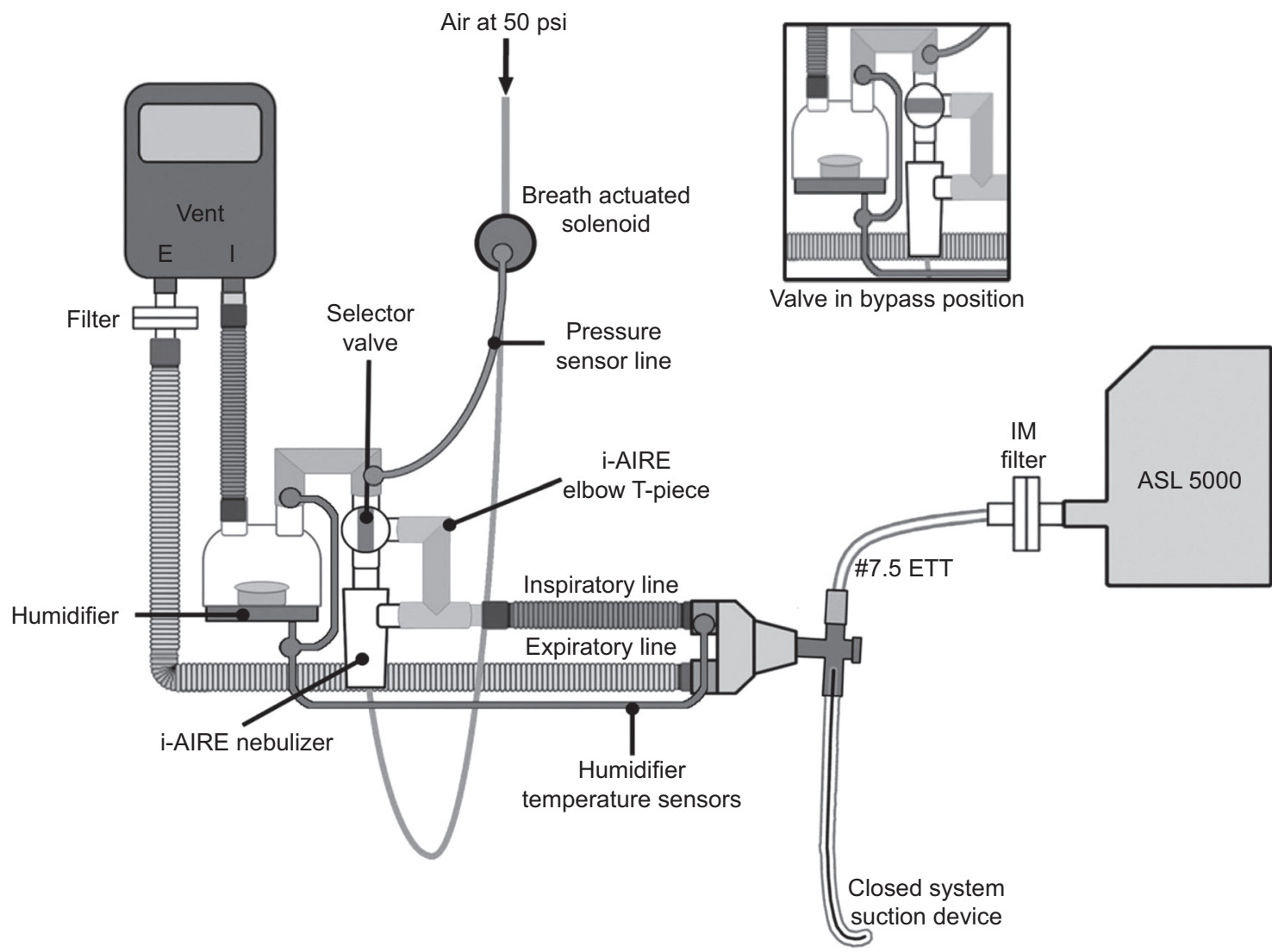

Fig. 4. The nebulizer in use during active humidification. Ventilator flow directed through the nebulizer. Insert: Selector valve turned, bypassing the nebulizer and directing flow to the conventional circuit.

Thermo Fischer Scientific, Waltham, Massachusetts) with the device located distal to the endotracheal tube; experiments were conducted with both HME and active humidification. For these measurements, the i-AIRE nebulizer was charged with $6 \mathrm{~mL}$ of normal saline solution mixed with a known amount of radioactivity. Aerosols were sampled over a 9-min period for a single ventilator setting (Avea, volume control-continuous mandatory ventilation, frequency 18 breaths $/ \mathrm{min}, \mathrm{V}_{\mathrm{T}} 500 \mathrm{~mL}$, flow $43 \mathrm{~L} / \mathrm{min}, \mathrm{T}_{\mathrm{I}} 0.7$ $\mathrm{s}$, PEEP $5 \mathrm{~cm} \mathrm{H}_{2} \mathrm{O}$, bias flow $2.0 \mathrm{~L} / \mathrm{m}$ ). Radioactivity on the cascade stages was measured by using a collimated rate meter (Ludlum Measurements, Sweetwater, Texas), and the distribution was plotted on log probability paper. Activity at the median defined the mass median aerodynamic diameter.

\section{Bias Flow}

A bias flow of $2.0 \mathrm{~L} / \mathrm{min}$ (a common default value) was used for most experiments. The effect of varying bias flow was measured at bias flows of $0.5,3.5$, and $5.0 \mathrm{~L} / \mathrm{m}$ at 2 ventilator settings: volume control-continuous mandatory ventilation, frequency 15 breaths/min,
$\mathrm{V}_{\mathrm{T}} 460 \mathrm{~mL}$, flow $55 \mathrm{~L} / \mathrm{m}, \mathrm{T}_{\mathrm{I}} 0.50 \mathrm{~s}$, and I:E 1:6.5; and volume control-continuous mandatory ventilation, frequency 20 breaths $/ \mathrm{min}, \mathrm{V}_{\mathrm{T}} 650 \mathrm{~mL}$, flow $40 \mathrm{~L} / \mathrm{m}, \mathrm{T}_{\mathrm{I}}$ $0.97 \mathrm{~s}$, and I:E 1:2.1. These experiments were carried out by using HME with an Avea ventilator, which allows adjustment of bias flow over this range.

\section{PEEP}

A PEEP setting of $5 \mathrm{~cm} \mathrm{H}_{2} \mathrm{O}$ was used for the majority of experiments. To test the potential effect of varying PEEPs, 10 and $15 \mathrm{~cm} \mathrm{H}_{2} \mathrm{O}$ was used with $\mathrm{T}_{\mathrm{I}}$ of $0.5,0.7$, $1.0 \mathrm{~s}$; duty cycle of $0.20,0.33$ using the Avea and Dräger ventilators.

\section{Analysis}

Aerosol delivery was defined as the IM\% or radioactivity on the IM filter reported as a percentage of nebulizer charge. To relate IM\% to the range of ventilator test conditions, IM\% was plotted as a function of $\mathrm{T}_{\mathrm{I}}$. $\mathrm{T}_{\mathrm{I}}$ was read directly on the ventilator and varied widely with different ventilator settings. Data were also plotted against 


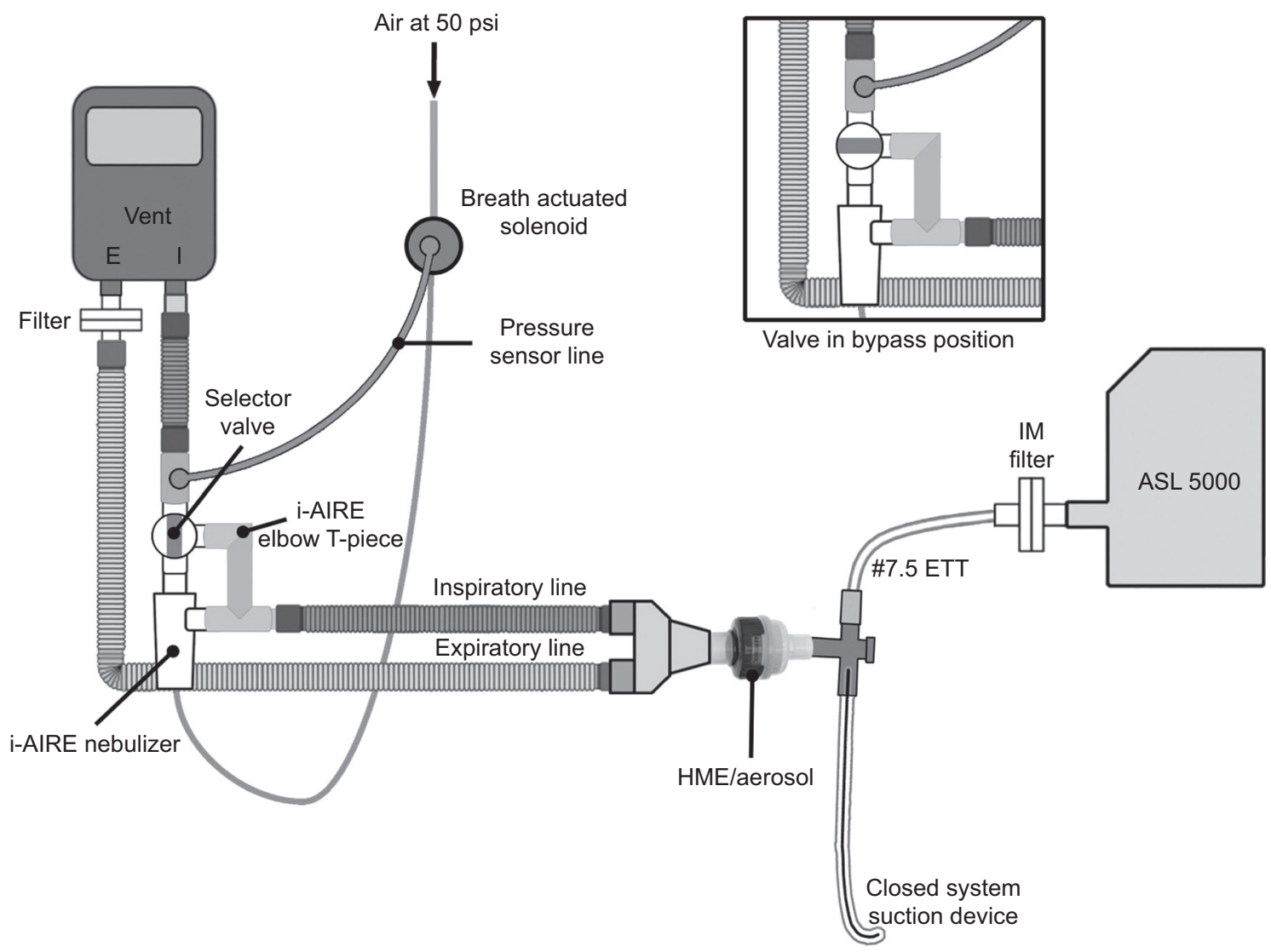

Fig. 5. Nebulizer in use during bypass-heat and moisture exchanger (HME). Ventilator flow directed through the nebulizer. Insert: Two-position valve is turned, bypassing the nebulizer and directing flow to the conventional circuit. $\mathrm{IM}=$ inhaled mass.

duty cycle $\left(\mathrm{T}_{\mathrm{I}} / \mathrm{T}_{\text {tot }}\right)$, the fraction of the breath that was inspiration; this parameter was calculated from ventilatorderived parameters and allowed comparison with data reported from other studies that measured aerosol delivery during mechanical ventilation.

To describe the distribution of radioactivity throughout the ventilator circuit a complete mass balance was carried out for 2 experiments. This process included measurement of $\mathrm{IM}$, nebulizer residual, deposition in ventilator tubing, expiratory filter, and endotracheal tube for the same settings during HME and active humidification. Radioactivity deposited in all parts of the circuit (nebulizer, tubing, and filters) was quantified by using a gamma camera (Maxi Camera 400 [General Electric, Horsholm, Denmark]; model 604/150/D [Power Computing, Austin, Texas]; Nuclear MAC, version 4.2.2 [Scientific Imaging, Campbell, California]).

\section{Statistics}

Data were analyzed by using GraphPad Prism version 8.1 for Mac OS X (GraphPad Software, San Diego, California) and reported as mean \pm SD. Group data were compared by using the Mann-Whitney rank sum test.

\section{Results}

\section{IM}

IM\% (\% neb charge): mean \pm SD [all data] $31.1 \% \pm$ 6.45 , no. $=83$; humidified $36.1 \% \pm 5.60$, no. $=26$; HME $28.8 \% \pm 5.51$, no. $=57$. Variation in IM percentage with different settings and modes of ventilation is shown on Figure 6. On the left, data are plotted against $\mathrm{T}_{\mathrm{I}}$, which illustrates IM\% with controlled ventilator settings for different ventilators. On the right, are data that could not be plotted against $\mathrm{T}_{\mathrm{I}}$ because the mode contained spontaneous-pressure supported breaths triggered by the ASL 5000 test lung and, therefore, there was no single value for $\mathrm{T}_{\mathrm{I}}$. The latter data are grouped by ventilatory mode.

In general, aerosol delivery was preserved for all settings and conditions with limited variability. A trend of increasing aerosol delivery was seen, with increasing duty cycle. Although there is considerable overlap between HME and humidified aerosol delivery, there is a small systematic shift that favors humidification, which was significant between humidification type (HME and active 


\section{Wet-Side Breath-Enhanced Jet Nebulization}

Table 1. Ventilator Settings: VC-CMV Mode

\begin{tabular}{|c|c|c|c|c|c|c|c|}
\hline Ventilator & Ventilator frequency, breaths/min & Set $\mathrm{V}_{\mathrm{T}}, \mathrm{mL}$ & Flow, L/min & $\mathrm{T}_{\mathrm{I}}, \mathrm{s}$ & $\mathrm{I}: \mathrm{E}$ & Duty Cycle $\left(\mathrm{T}_{\mathrm{I}} / \mathrm{T}_{\mathrm{tot}}\right)$ & Waveform \\
\hline Avea & 12 & 700 & 42 & 1.00 & $1: 3.8$ & 0.20 & Const \\
\hline Avea & 15 & 460 & 55 & 0.54 & $1: 6.5$ & 0.14 & Const \\
\hline Avea & 18 & 500 & 60 & 0.70 & $1: 3.8$ & 0.21 & Const \\
\hline Avea & 20 & 650 & 40 & 0.97 & $1: 2.1$ & 0.32 & Const \\
\hline Dräger & 12 & 700 & 45 & 1.00 & $1: 4.0$ & 0.20 & Decel \\
\hline Dräger & 12 & 700 & Autoflow & 1.00 & 1: 4.0 & 0.20 & Decel \\
\hline Dräger & 15 & 460 & 59 & 0.53 & $1: 6.5$ & 0.13 & Const \\
\hline Dräger & 18 & 500 & Autoflow & 0.70 & $1: 3.7$ & 0.21 & Decel \\
\hline Dräger & 20 & 650 & 44 & 0.98 & 1: 2.1 & 0.33 & Const \\
\hline Servo & 15 & 460 & 59 & 0.55 & 1: 6.3 & 0.14 & Decel \\
\hline Servo & 18 & 500 & 43 & 0.70 & 1: 3.8 & 0.21 & Decel \\
\hline Servo & 20 & 650 & 40 & 1.00 & 1: 2.1 & 0.33 & Decel \\
\hline $\begin{array}{l}\text { Three ventilato } \\
\text { VC-CMV }=\text { vo } \\
T_{1}=\text { inspirator } \\
\mathrm{I}: \mathrm{E}=\text { inspirato } \\
\mathrm{T}_{\text {tot }}=\mathrm{T}_{\mathrm{i}}+\mathrm{T}_{\mathrm{e}} \\
\text { Const }=\text { consta } \\
\text { Decel }=\text { decele }\end{array}$ & $\begin{array}{l}\text { ds that use heated wire humidification or bypas } \\
\text { control-continuous mandatory ventilation } \\
\text { expiratory ratio } \\
\text { w waveform } \\
\text { wavform }\end{array}$ & -valved HME, PEI & $\mathrm{cm} \mathrm{H}_{2} \mathrm{O}$, bias flov & $\mathrm{L} / \mathrm{m}$ & & & \\
\hline
\end{tabular}

Table 2. Ventilator Settings: PC-CMV Mode

\begin{tabular}{|c|c|c|c|c|c|c|c|}
\hline Ventilator & Ventilator frequency breaths/min & Set $\mathrm{V}_{\mathrm{T}}, \mathrm{mL}$ & $\mathrm{PIP}(\mathrm{PC}), \mathrm{cm} \mathrm{H}_{2} \mathrm{O}$ & $\mathrm{T}_{\mathrm{I}}, \mathrm{s}$ & $\mathrm{I}: \mathrm{E}$ & Duty Cycle $\left(T_{1} / T_{\text {tot }}\right)$ & Waveform \\
\hline Avea & 18 & 470 & $15(10)$ & 0.85 & $1: 5.3$ & 0.26 & Decel \\
\hline Servo & 20 & 500 & $15(10)$ & 0.90 & $1: 2.3$ & 0.30 & Decel \\
\hline Dräger & 18 & 415 & $15(10)$ & 0.70 & $1: 3.2$ & 0.24 & Decel \\
\hline $\begin{array}{l}\text { Three ventilato } \\
\text { PC-CMV }=\text { pre } \\
\text { PIP }=\text { peak ins } \\
\text { PC }=\text { pressure } \\
\mathrm{T}_{\mathrm{I}}=\text { inspirator } \\
\mathrm{I}: \mathrm{E}=\text { inspirato } \\
\mathrm{T}_{\text {tot }}=\mathrm{T}_{\mathrm{i}}+\mathrm{T}_{\mathrm{e}} \\
\text { Decel }=\text { decele }\end{array}$ & $\begin{array}{l}\text { Inds that use heated wire humidification or byp } \\
\text { e control-continuous mandatory ventilation } \\
\text { ory pressure } \\
\text { rol level above PEEP } \\
\text { ee } \\
\text { expiratory ratio } \\
\text { g wavform }\end{array}$ & ble-valved HME, I & P $5.0 \mathrm{~cm} \mathrm{H}_{2} \mathrm{O}$, bias flow 2.0 & & & & \\
\hline
\end{tabular}

Table 3. Ventilator Settings: VC-IMV + PS Mode

\begin{tabular}{|c|c|c|c|c|c|c|c|}
\hline Ventilator & $\begin{array}{c}\text { Frequency (ASL/vent), } \\
\text { breaths/min }\end{array}$ & $\begin{array}{l}\text { Set } V_{\mathrm{T}} / \mathrm{ASL} \\
(\mathrm{PS}) \mathrm{VT}, \mathrm{mL}\end{array}$ & $\mathrm{PS}, \mathrm{cm} \mathrm{H}_{2} \mathrm{O}$ & Flow, L/min & Set $\mathrm{T}_{\mathrm{I}} / \mathrm{s}$ & $\mathrm{I}: \mathrm{E}$ & Waveform \\
\hline Avea & $12 / 5$ & $700 / 620$ & 10 & 43 & 1.0 & $1: 5.0$ & Const \\
\hline Dräger & $12 / 4$ & $500 / 390$ & 8 & Autoflow & 0.70 & $1: 6.0$ & Decel \\
\hline Servo & $18 / 10$ & $500 / 460$ & 10 & 52 & 0.65 & $1: 5.7$ & Decel \\
\hline $\begin{array}{l}\text { Three ventilato } \\
\text { VC-IMV }+ \text { PS } \\
\text { ASL }=\text { rate tris } \\
\text { Vent }=\text { rate set } \\
\text { ASL }(\mathrm{PS}) \mathrm{V}_{\mathrm{T}}= \\
\mathrm{I}: \mathrm{E}=\text { inspirato } \\
\mathrm{T}_{\mathrm{I}}=\text { inspirator } \\
\text { Const }=\text { consta } \\
\text { Decel }=\text { decele }\end{array}$ & $\begin{array}{l}\text { that use heated wire humidificati } \\
\text { me control-intermittent mandatory } \\
\text { y ASL test lung } \\
\text { ilator } \\
\text { lume generated by ASL triggered } \\
\text { iratory ratio } \\
\text { waveform } \\
\text { aveform }\end{array}$ & $\begin{array}{l}\text { passable-valved HN } \\
\text { tion }+ \text { pressure sup }\end{array}$ & P $5.0 \mathrm{~cm} \mathrm{H}_{2} \mathrm{O}$, bias & $0 \mathrm{~L} / \mathrm{m}$ & & & \\
\hline
\end{tabular}

humidification) for all data $(P<.001)$, CMV modes $(P<$ $.001)$, and pressure support-airway pressure release ventilation modes $(P<.001)$. Bias flow had no effect as illustrated by the points at $\mathrm{T}_{\mathrm{I}}$ of 0.5 and $1.0 \mathrm{~s}$. (Fig. 6). PEEP had no effect, 10 and $15 \mathrm{~cm} \mathrm{H}_{2} \mathrm{O}$ were tested as illustrated by points at $\mathrm{T}_{\mathrm{I}} 0.5,0.7$, and $1.0 \mathrm{~s}$ (Fig. 6). 


\section{Wet-Side BREath-EnHANCEd Jet Nebulization}

Table 4. Ventilator Settings: PRVC-IMV + PS Mode

\begin{tabular}{|c|c|c|c|c|c|c|c|}
\hline Ventilator & $\begin{array}{c}\text { Frequency (ASL/vent), } \\
\text { breaths/min }\end{array}$ & $\begin{array}{l}\text { Set } \mathrm{V}_{\mathrm{T}} / \mathrm{ASL} \\
(\mathrm{PS}) \mathrm{V}_{\mathrm{T}}, \mathrm{mL}\end{array}$ & $\begin{array}{c}\mathrm{PS} \\
\mathrm{cm} \mathrm{H}_{2} \mathrm{O}\end{array}$ & $\begin{array}{c}\mathrm{PIP} \\
\mathrm{cm} \mathrm{H}_{2} \mathrm{O}\end{array}$ & Mand $T_{i}, s$ & $\mathrm{I}: \mathrm{E}$ & Waveform \\
\hline Avea & $15 / 5$ & $350 / 310$ & 5 & 15 & 0.85 & $1: 3.7$ & Decel \\
\hline Avea & $18 / 10$ & $500 / 350$ & 7 & 12 & 0.70 & $1: 3.9$ & Decel \\
\hline Servo & $18 / 10$ & $550 / 312$ & 5 & 15 & 0.9 & $1: 5.7$ & Decel \\
\hline
\end{tabular}

Two ventilator brands that use heated wire humidification or bypassable-valved HME, PEEP $5.0 \mathrm{~cm} \mathrm{H}_{2} \mathrm{O}$, bias flow $2.0 \mathrm{~L} / \mathrm{m}$.

PRVC-IMV + PS = pressure-regulated volume control with synchronized intermittent mandatory ventilation + pressure support

$\mathrm{ASL}=$ rate triggered by ASL test lung

Vent $=$ rate set on ventilator

ASL (PS) $V_{\mathrm{T}}=$ tidal volume generated by ASL triggered breaths

$\mathrm{PS}=$ pressure support

$\mathrm{PIP}=$ peak inspiration pressure

Mand $\mathrm{T}_{\mathrm{i}}=\mathrm{T}_{\mathrm{i}}$ for set ventilator rate

$\mathrm{I}: \mathrm{E}=$ inspiratory to expiratory ratio

$\mathrm{T}_{\mathrm{I}}=$ inspiratory time

Const $=$ constant flow waveform

Decel $=$ decelerating waveform

Table 5. Ventilator Settings: CPAP + PS Mode

\begin{tabular}{|c|c|c|c|c|c|}
\hline Ventilator & Frequency (ASL/vent), breaths/min & $\operatorname{ASL}(\mathrm{PS}) \mathrm{V}_{\mathrm{T}}, \mathrm{mL}$ & $\mathrm{PS}, \mathrm{cm} \mathrm{H}_{2} \mathrm{O}$ & $\mathrm{T}_{\mathrm{I}}, \mathrm{s}$ & Waveform \\
\hline Avea & $12 / 0$ & 280 & 10 & 1.08 & Decel \\
\hline Dräger & $12 / 0$ & 598 & 10 & $\sim 1.1$ & Decel \\
\hline Dräger & $12 / 0$ & 475 & 8 & $\sim 1.1$ & Decel \\
\hline Servo & $12 / 0$ & 480 & 8 & $\sim 1.1$ & Decel \\
\hline Servo & $12 / 0$ & 480 & 5 & $\sim 1.1$ & Decel \\
\hline
\end{tabular}

Three ventilator brands that use heated wire humidification or bypassable-valved HME, PEEP $5.0 \mathrm{~cm} \mathrm{H}_{2} \mathrm{O}$, bias flow $2.0 \mathrm{~L} / \mathrm{m}$.

$\mathrm{CPAP}+\mathrm{PS}=$ continuous positive airway pressure + pressure support

$\mathrm{ASL}=$ rate triggered by ASL test lung

Vent $=$ rate set on ventilator

ASL $(\mathrm{PS}) \mathrm{V}_{\mathrm{T}}=$ tidal volume generated by ASL triggered breaths

$\mathrm{PS}=$ pressure support

$\mathrm{T}_{\mathrm{I}}=$ inspiratory time

Const $=$ constant flow waveform

Decel $=$ decelerating waveform

Table 6. Ventilator Settings: APRV and APRV (Bi-Vent)

\begin{tabular}{|c|c|c|c|c|c|c|}
\hline Ventilator & Frequency (ASL/vent), breaths/min & Vent $\mathrm{V}_{\mathrm{T}} / \mathrm{ASL} \mathrm{V}_{\mathrm{T}}, \mathrm{mL}$ & $\mathrm{P}_{\text {high }} / \mathrm{P}_{\text {low }}, \mathrm{cm} \mathrm{H}_{2} \mathrm{O}$ & $\mathrm{T}_{\text {high, }} \mathrm{s}$ & $\mathrm{T}_{\text {low }}, \mathrm{s}$ & Waveform \\
\hline Avea & $12 / 0$ & $488 / 500$ & $25 / 0$ & 4.4 & 0.60 & ND \\
\hline Dräger & $12 / 0$ & $591 / 537$ & $25 / 0$ & 4.4 & 0.60 & ND \\
\hline Servo* & $12 / 0$ & $480 / 500$ & $25 / 0$ & 4.4 & 0.60 & ND \\
\hline
\end{tabular}

Three ventilator brands that use heated wire humidification or bypassable-valved HME, PEEP $5.0 \mathrm{~cm} \mathrm{H}_{2} \mathrm{O}$, bias flow $2.0 \mathrm{~L} / \mathrm{m}$.

*APRV(Bi-Vent).

$\mathrm{APRV}=$ airway pressure release ventilation (or BiVent)

$\mathrm{ASL}=$ rate triggered by ASL test lung

Vent $=$ rate set on ventilator

$\mathrm{PS}=$ pressure support

ASL $(\mathrm{PS}) \mathrm{V}_{\mathrm{T}}=$ tidal volume generated by ASL triggered breaths

$\mathrm{P}_{\text {high }}=$ amplitude of time triggered mandatory breath

$\mathrm{P}_{\text {low }}=$ expiratory pressure

$\mathrm{T}_{\text {high }}=$ duration of Phigh

$\mathrm{T}_{\text {low }}=$ expiratory time or release time

$\mathrm{T}_{\mathrm{I}}=$ inspiratory time 

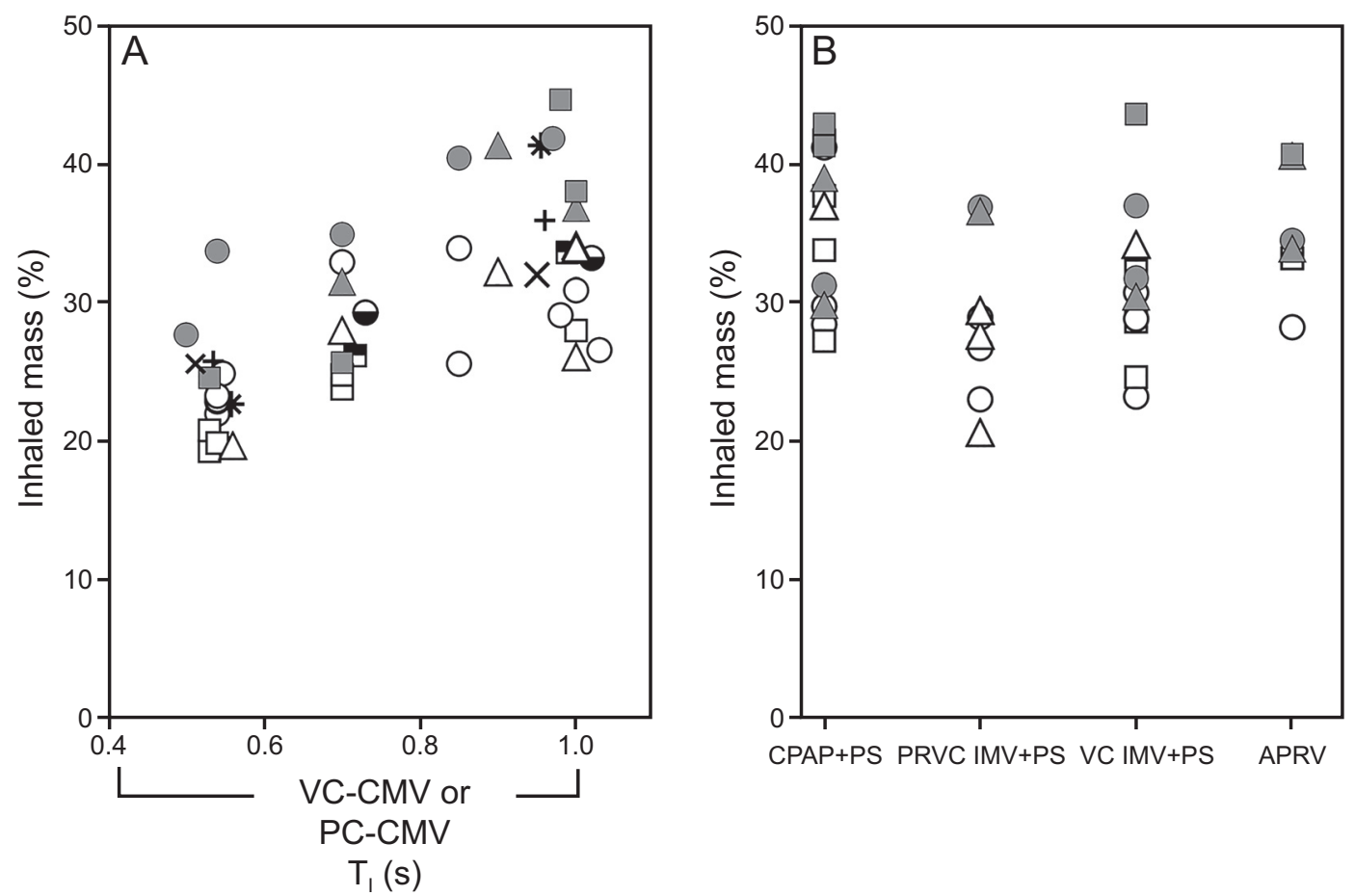

Fig. 6. Inhaled mass (IM) as a percentage of nebulizer charge versus ventilator mode: inspiratory time ( $\left.\mathrm{T}_{1}\right)$ left; pressure-supported modes right; active humidification, filled symbols; bypassable HME (BP-HME), open symbols; Avea ( $)$ ), Drager ( $\square$ ), Servo-i ( $\triangle$ ). PEEP studies: Avea ( $\bullet$ ), Drager (曷). Bias flow was $0.5 \mathrm{~L} / \mathrm{m}(\mathbf{*}), 3.5 \mathrm{~L} / \mathrm{m}(\mathbf{+}), 5.0 \mathrm{~L} / \mathrm{m}$ (*). Nebulizer flow $3.5 \mathrm{~L} / \mathrm{m}$. VC-CMV = volume control-continuous mandatory ventilation, $\mathrm{PC}-\mathrm{CMV}=$ pressure control-continuous mandatory ventilation; CPAP $+\mathrm{PS}=$ continuous positive airway pressure plus pressure support; PRVC IMV + PS = pressure-regulated volume control with SIMV + pressure support; VC-IMV + PS = volume control-intermittent mandatory ventilation plus pressure support (VC-synchronized intermittent mandatory ventilation + PS); APRV = airway pressure release ventilation (or BiVent).

\section{Residual Volume}

Residual volume percentage (\% neb charge remaining in the nebulizer after treatment completed) was the following: mean \pm SD [all data] $29.6 \% \pm 11.2$, no. $=81$; humidified $16.3 \% \pm 7.04$, no. $=26$; and $\operatorname{HME} 35.9 \% \pm 6.00$, no. $=56$, with a significant difference between HME and active humidification $(P<.001)$.

\section{Nebulizer Flow: Effect on Ventilator Settings}

Data for values of $\mathrm{V}_{\mathrm{T}}$ measured for 4 different ventilator settings before and during nebulization are listed in Table 7. All extraneous filters and attachments to the circuit were removed to minimize circuit leaks. $\mathrm{V}_{\mathrm{T}}$ was reported in 3 ways; (1) defined by the set volume $\left(\mathrm{V}_{\mathrm{T}}\right)$, (2) monitored by the ventilator (Exhaled $\mathrm{V}_{\mathrm{T}}$ ), and (3) measured directly by the ASL 5000 test lung volume. Added nebulizer flow during breath-actuated nebulization resulted in small, insignificant changes in $\mathrm{V}_{\mathrm{T}}(\mathrm{mL})$ measured by both the ventilator (Exhaled $\mathrm{V}_{\mathrm{T}}-5.0 \pm$ $12.9 \mathrm{~mL} ; P=.75)$ and the ASL test lung volume (25 \pm $14.5 \mathrm{~mL} ; P=.13)$.

\section{Particle Distribution}

The particle distributions of captured aerosol at the distal tip of the endotracheal tube are shown in Figure 7. The mass median aerodynamic diameter was $1.04 \mu \mathrm{m}$ in the HME mode and $1.34 \mu \mathrm{m}$ during active humidification. Approximately $2 \%$ of the particles were $>5 \mu \mathrm{m}$.

\section{Mass Balance}

The distribution of radioactivity throughout the ventilator circuit for active humidification and HME are listed in Table 8 . For the same ventilator setting (frequency 18 breaths $/ \mathrm{min}$, $\mathrm{V}_{\mathrm{T}} 500 \mathrm{~mL}$, inspiratory flow $43 \mathrm{~L} / \mathrm{m}$, constant wave form), nebulizer residual was reduced during humidification by $>50 \%$ (39.4-14.6\%). With active humidification, circuit deposition was increased throughout the circuit but, because of the reduced nebulizer residual, IM\% was increased (35.0 vs $29.4 \%$ ). The latter findings were seen for all measurements of nebulizer output reported in Figure 6. Endotracheal tube losses were small, consistent with the terminal particle distribution. Losses on the exhalation filter were relatively low, an effect of breath actuation. 


\section{Wet-Side BREath-EnHANCEd Jet Nebulization}

Table 7. Effect of Added Nebulizer Flow on Delivered $V_{T}$

\begin{tabular}{|c|c|c|c|}
\hline Parameter & Set $\mathrm{V}_{\mathrm{T}}, \mathrm{mL}$ & Exhaled $\mathrm{V}_{\mathrm{T}}, \mathrm{mL}^{*}$ & ASL $\mathrm{V}_{\mathrm{T}}, \mathrm{mL}^{\dagger}$ \\
\hline \multicolumn{4}{|l|}{$\mathrm{V}_{\mathrm{T}}=460 \mathrm{~mL} / \mathrm{T}_{\mathrm{I}}=0.70 \mathrm{~s} / \mathrm{DC}=0.20$} \\
\hline No NEB & 460 & 410 & 426 \\
\hline With NEB & 460 & 400 & 447 \\
\hline$\Delta$ & & -10.0 & 21.0 \\
\hline \multicolumn{4}{|l|}{$\mathrm{V}_{\mathrm{T}}=500 \mathrm{~mL} / \mathrm{T}_{\mathrm{I}}=0.70 \mathrm{~s} / \mathrm{DC}=0.20$} \\
\hline No NEB & 500 & 460 & 455 \\
\hline With NEB & 500 & 460 & 486 \\
\hline$\Delta$ & & 0.0 & 31.0 \\
\hline \multicolumn{4}{|l|}{$\mathrm{V}_{\mathrm{T}}=690 \mathrm{~mL} / \mathrm{T}_{\mathrm{I}}=0.80 \mathrm{~s} / \mathrm{DC}=0.24$} \\
\hline No NEB & 690 & 630 & 629 \\
\hline With NEB & 690 & 610 & 636 \\
\hline$\Delta$ & & -20.0 & 7.0 \\
\hline \multicolumn{4}{|l|}{$\mathrm{V}_{\mathrm{T}}=650 \mathrm{~mL} / \mathrm{T}_{\mathrm{I}}=1.01 \mathrm{~s} / \mathrm{DC}=0.33$} \\
\hline No NEB & 650 & 610 & 593 \\
\hline With NEB & 650 & 620 & 634 \\
\hline$\Delta$ & & 10.0 & 41.0 \\
\hline $\begin{array}{l}\text { Set tidal volume }\left(\mathrm{SET} \mathrm{V}_{\mathrm{T}}\right) \text {, monitored by ventilator } \\
* \text { Average } \Delta \mathrm{E} \mathrm{V}_{\mathrm{T}}=-5.0 \mathrm{~mL} \text {. } \\
+ \text { Average } \Delta \mathrm{ASL} \mathrm{V}_{\mathrm{T}}=25.0 \mathrm{~mL} \text {. } \\
\mathrm{V}_{\mathrm{T}}=\text { tidal volume } \\
\text { ASL } \mathrm{V}_{\mathrm{T}}=\text { tidal volume generated by ASL triggere } \\
\mathrm{T}_{\mathrm{I}}=\text { inspiratory time } \\
\mathrm{DC}=\text { duty cycle } \\
\mathrm{NEB}=\text { nebulizer } \\
\text { No NEB }=\mathrm{V}_{\mathrm{T}} \text { measured when nebulizer bypassed } \\
\text { With NEB }=\mathrm{V}_{\mathrm{T}} \text { measured during nebulization }\end{array}$ & ASL test lung (AS & & \\
\hline
\end{tabular}

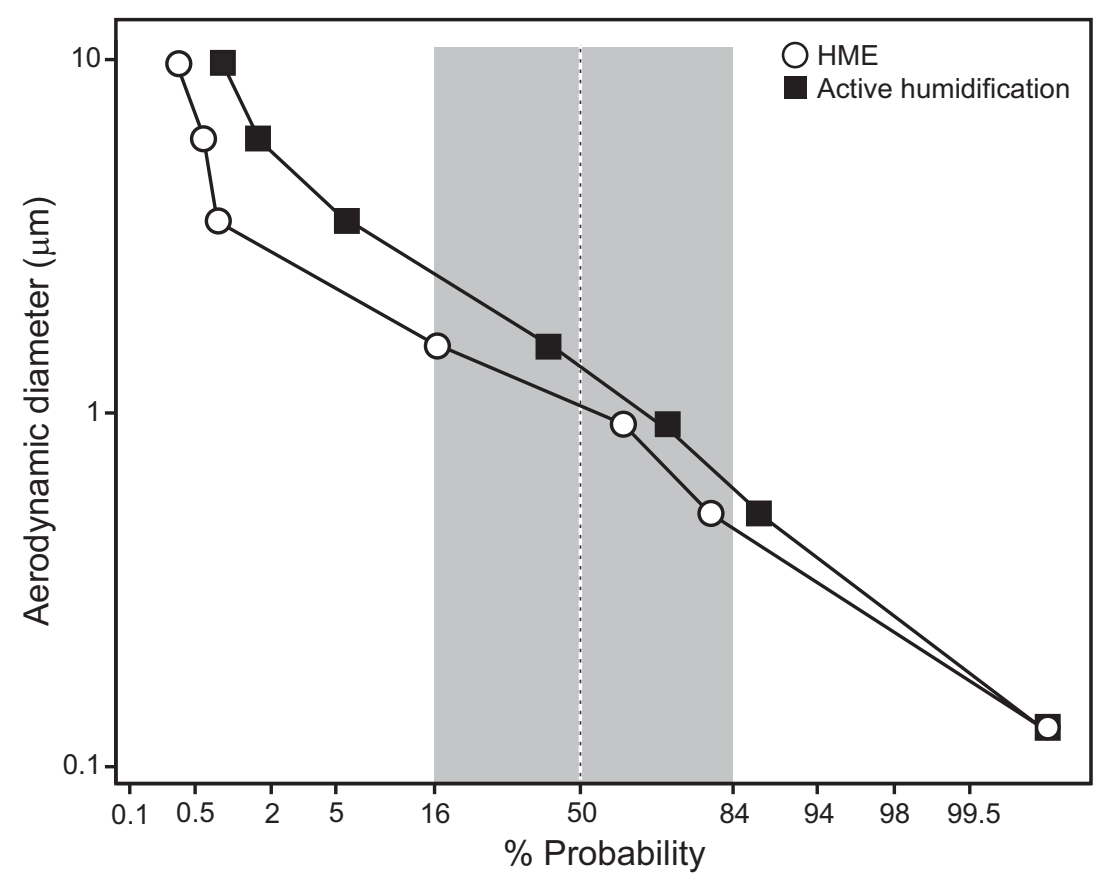

Fig. 7. Aerodynamic particle distribution measured via Marple cascade impactor placed in line between the endotracheal tube and inhaled mass filter. Volume control-continuous mandatory ventilation [VC-CMV], rate 18, tidal volume $\left(\mathrm{V}_{T}\right) 500 \mathrm{~mL}$, flow $43 \mathrm{~L} / \mathrm{min}$, inspiratory time ( $\left.\mathrm{T}_{1}\right)$ $0.7 \mathrm{~s}$, PEEP $5 \mathrm{~cm} \mathrm{H} \mathrm{H}_{2} \mathrm{O}$, bias flow $2.0 \mathrm{~L} / \mathrm{m}$. The log particle size for each cascade stage was plotted against probability. Mass median aerodynamic diameter $(\mathrm{MMAD})$ : bypassable-valved $\mathrm{HME}=1.04 \mu \mathrm{m}$; active humidification $=1.34 \mu \mathrm{m}$. $\mathrm{HME}=$ heat and moisture exchanger. 
Table 8. Mass Balance

\begin{tabular}{|c|c|c|}
\hline Parameter & Active Humidification (\%) & $\operatorname{HME}(\%)$ \\
\hline Nebulizer residual & 14.6 & 39.4 \\
\hline Inhaled mass filter & 35.0 & 29.4 \\
\hline Expiratory filter & 13.6 & 9.2 \\
\hline Ventilator circuit & 27.0 & 13.2 \\
\hline ETT & 2.8 & 2.7 \\
\hline Total recovery & 93.0 & 95.2 \\
\hline \multicolumn{3}{|c|}{$\begin{array}{l}\text { Tidal volume } 500 \mathrm{~mL}, 18 \text { breaths } / \mathrm{min} \text {, flow } 43 \mathrm{~L} / \mathrm{min} \text {, inspiratory time } 0.7 \mathrm{~s} \text {, PEEP } 5 \mathrm{~cm} \mathrm{H}_{2} \mathrm{O} \text {, } \\
\text { bias flow } 2.0 \mathrm{~L} / \mathrm{m} \text {. } \\
\text { HME = heat and moisture exchanger } \\
\text { ETT = endotracheal tube }\end{array}$} \\
\hline
\end{tabular}

\section{Discussion}

This study demonstrated that the i-AIRE nebulizer with the combination of breath enhancement and breath actuation provided predictable drug delivery over a wide range of ventilator settings, regardless of the type of ventilator or mode of humidification. The i-AIRE nebulizer was far more efficient than previously reported jet-driven devices. For example, Miller et $\mathrm{al}^{5}$ reported similar values of IM\% for a single ventilator setting when using breath actuation (provided directly by the ventilator) and high nebulizer jet flow $(8 \mathrm{~L} / \mathrm{min})$, but they reported a treatment time of $1 \mathrm{~h}$ for only $2 \mathrm{~mL}$ of nebulizer charge. The i-AIRE nebulized $6 \mathrm{~mL}$ in the same time period, which suggests at least a $300 \%$ increase in output for the i-AIRE system effected by breath enhancement (eg, compared with AeroTech II $^{5}$ (Biodex Medical Systems, Shirley, New York).

To our knowledge, there are no approved medications for inhalation specifically on a ventilator circuit, and all commonly used drugs are used off label. To develop approved aerosolized antibiotic therapy, our group focused on controlling nebulizer delivery in patients who were intubated because of the general understanding that nebulizer function is affected by many variables. This point is illustrated in Figure 1, which contains output data for many reported studies that contained enough information to allow calculation of a duty cycle $\left(\mathrm{T}_{\mathrm{I}}\right.$, in general, was not available). ${ }^{1,2,5,8,16-21}$ As shown in the figure IM\% varied widely (2.7-41\%), based on nebulizer technology, breathing pattern, position in the circuit, and the presence of humidification.

Without some form of superimposed control, it is easy to see why a dose-dependent drug with a delayed clinical response would be hard to study and to prove efficacy. Previous studies performed at a single site indicated that the ventilator type, use of humidification, and ventilator modes must be rigorously controlled for clinical antibiotic success. ${ }^{5,22,23,27}$ This type of control was not possible in multi-center studies, and failure to control dose delivery may have contributed to the recent reported failures of multi-center antibiotic protocols. ${ }^{28-30}$ The i-AIRE system reduces the dosing variability (23-41\% vs $2.7-41 \%$ ) seen with current technologies and functions reliably for most described forms of invasive ventilation across a wide range of commonly used settings, with preservation of dose delivery during active and passive humidification.

Ehrmann et $\mathrm{al}^{13}$ evaluated inspiratory synchronization during ventilator-integrated, breath-actuated nebulization. They assessed nebulizer flow at the beginning and end of inspiration and found that nebulization continued up to $1 \mathrm{~s}$ after the end of inspiration, which resulted in as much as $80 \%$ of nebulization occurring during the expiratory phase. ${ }^{13}$ Ehrmann et $\mathrm{al}^{13}$ stated that gas compression and decompression proximal to the nebulizer are probably major determinants of persistent nebulization during expiration. Analysis of their data suggests that pressure in the nebulizer line due to the high resistance in the nebulizer orifice prevents closure of the ventilator solenoid. ${ }^{13}$ Failure of solenoid closure in the ventilator allows nebulization to continue during expiration. To prevent this phenomenon, our system used an independent solenoid that actively opened and closed, which prevented increased expiratory losses.

Jet nebulizers require a defined flow of gas and pressure to generate aerosol. Commercial ventilators do not universally provide breath actuation or standardized flow and pressure. ${ }^{12}$ The i-AIRE system relies on wall gas and pressure, and a standardized nebulizer flow of $3.5 \mathrm{~L} / \mathrm{m}$, avoiding unpredictable nebulizer-ventilator combinations. Jet nebulizers powered from hospital wall gas may affect ventilator displays because nebulizer gases enter the expiratory line. However, the brief introduction of nebulizer gas during breath-actuated inspiration was not readily detected (Table 7). The average added $\mathrm{V}_{\mathrm{T}}$ to the circuit of $25 \mathrm{~mL}$ is $5 \%$ of a $450 \mathrm{~mL} \mathrm{~V} \mathrm{~V}_{\mathrm{T}}$; this added volume is much less than that resulting from a conventional jet nebulizer, which runs at $6-8 \mathrm{~L} / \mathrm{m}$ at any $\mathrm{V}_{\mathrm{T}}$.

Added humidity has been reported to be an unpredictable factor that affects aerosol delivery. ${ }^{2,5,7,16,31-33}$ In early studies, our group was one of the first to report losses in aerosol delivery during active humidification, of $\sim 50 \%$. $^{5,7}$ In the present study, when using the i-AIRE nebulizer and specialized wet-sided nebulization, we observed similar dose delivery between both active humidification and HME. Analysis of these data indicates that dosing of the patient would not be significantly affected with i-AIRE, with or without active humidification. The mass balance analysis and particle distribution data show that wet-side humidification significantly increased nebulizer output. As shown in the mass balance data, with humidification there is a decrease in residual volume.

Most jet nebulizers operate by using dry gas. The residual volume represents liquid that contains a drug that coats the walls of the nebulizer with some liquid drying on the 


\section{Wet-Side Breath-Enhanced Jet Nebulization}

walls and failing to be recycled into the nebulizer bowl. The i-AIRE system, ventilated with humidified air, demonstrates reduced wall losses, which makes more liquid available for nebulization. The increase in nebulizer efficiency is balanced by increased losses in the circuit (likely due to particle growth). These effects result in similar IM\% and mass median aerodynamic diameter, with and without active humidification.

The effect of bias flow on aerosol delivery has been previously studied. ${ }^{1,5}$ Miller et $\mathrm{al}^{5}$ measured an effect with the nebulizer located in the inspiratory limb. However, they tested bias flows of $10-15 \mathrm{~L} / \mathrm{m} .^{5}$ Ari et $\mathrm{al}^{1}$ assessed the effect of 2.0 and $5.0 \mathrm{~L} / \mathrm{m}$ in 2 circuit positions that compared a jet nebulizer and a vibrating mesh nebulizer. This group found that bias flow had a statistically significant effect when placed $15 \mathrm{~cm}$ from the Y-piece in the inspiratory limb but not when placed close to the ventilator. ${ }^{1}$ In the current study, $2.0 \mathrm{~L} / \mathrm{min}$ was used for all routine experiments because this is a common default value on adult ventilators that both allow for adjustment of bias flow and with a fixed bias flow. The effect of bias flow $(0.5,3.5$, and $5 \mathrm{~L} / \mathrm{m})$ was tested by using an Avea ventilator, which provided for adjustment of bias flow. No effect was detected on IM\%.

The nebulizer-circuit combination is a prototype design and subject to untested clinical variables. We did not test all commercially available ventilators and clinically relevant situations. This study established a potential design that, if carried forward, may allow therapeutic trials of important drugs whose clinical effects cannot be assessed in real time at the bedside.

\section{Conclusions}

Because aerosol delivery device-mechanical ventilator combinations are not standardized for drug delivery, there can be substantial variation among practitioners in the practice of aerosol administration. The i-AIRE system minimizes interprovider variability, with a nebulizer-circuit combination that provides predictable drug delivery, with and without active humidification, and avoiding potential humidifier contamination.

\section{ACKNOWLEDGMENTS}

The authors thank Lorraine Morra for her help in data analysis and preparation of the manuscript, Vijay Shukla and Akanksha Hande, of InspiRx, for assistance with nebulizer circuit development and design. The authors also thank Stony Brook University Hospital Respiratory Care Department, Dräger Medical, and Fisher Paykel for the loan of equipment used in this study.

\section{REFERENCES}

1. Ari A, Atalay OT, Harwood R, Sheard MM, Aljamhan EA, Fink JB. Influence of nebulizer type, position, and bias flow on aerosol drug delivery in simulated pediatric and adult lung models during mechanical ventilation. Respir Care 2010;55(7):845-851.

2. Ari A, Areabi H, Fink JB. Evaluation of aerosol generator devices at 3 locations in humidified and non-humidified circuits during adult mechanical ventilation. Respir Care 2010;55(7):837-844.

3. Hughes J, Saez T. Effects of nebulizer mode and position in a mechanical ventilator circuit on dose efficiency. Respir Care 1987;32 (12):1131-1135.

4. Berlinski A, Willis JR. Albuterol delivery by 4 different nebulizers placed in 4 different positions in a pediatric ventilator in vitro model. Respir Care 2013;58(7):1124-1133.

5. Miller DD, Amin MM, Palmer LB, Shah AR, Smaldone GC. Aerosol delivery and modern mechanical ventilation: in vitro/in vivo evaluation. Am J Respir Crit Care Med 2003;168(10):1205-1209.

6. O'Riordan TG, Palmer LB, Smaldone GC. Aerosol deposition in mechanically ventilated patients. Optimizing nebulizer delivery. Am J Respir Crit Care Med 1994;149(1):214-219.

7. O'Riordan TG, Greco MJ, Perry RJ, Smaldone GC. Nebulizer function during mechanical ventilation. Am Rev Respir Dis 1992;145(5):1117 1122.

8. Diot P, Morra L, Smaldone GC. Albuterol delivery in a model of mechanical ventilation. Comparison of metered-dose inhaler and nebulizer efficiency. Am J Respir Crit Care Med 1995;152(4 Pt 1):1391-1394.

9. O'Doherty MJ, Thomas SH, Page CJ, Treacher DF, Nunan TO. Delivery of a nebulized aerosol to a lung model during mechanical ventilation. Effect of ventilator settings and nebulizer type, position, and volume of fill. Am Rev Respir Dis 1992;146(2):383-388.

10. Ari A, Fink JB. Factors affecting bronchodilator delivery in mechanically ventilated adults. Nurs Crit Care 2010;15(4):192-203.

11. Berlinski A, Willis JR. Effect of tidal volume and nebulizer type and position on albuterol delivery in a pediatric model of mechanical ventilation. Respir Care 2015;60(10):1424-1430.

12. McPeck M, O'Riordan T, Smaldone GC. Choice of mechanical ventilator: influence on nebulizer performance. Respir Care 1993;38 (8):887-895.

13. Ehrmann S, Lyazidi A, Louis B, Isabey D, Le Pennec D, Brochard L, Apiou-Sbirlea G. Ventilator-integrated jet nebulization systems: tidal volume control and efficiency of synchronization. Respir Care 2014;59(10):1508-1516.

14. Gowda AA, Cuccia AD, Smaldone GC. Reliability of vibrating mesh technology. Respir Care 2017;62(1):65-69.

15. Hess D, Fisher D, Williams P, Pooler S, Kacmarek RM. Medication nebulizer performance. Effects of diluent volume, nebulizer flow, and nebulizer brand. Chest 1996;110(2):498-505.

16. Ehrmann S, Chastre J, Diot P, Lu Q. Nebulized antibiotics in mechanically ventilated patients: a challenge for translational research from technology to clinical care. Ann Intensive Care 2017;7(1):78.

17. Anderson AC, Dubosky MN, Fiorino KA, Quintana V, Kaplan CA, Vines DL. The effect of nebulizer position on aerosolized epoprostenol delivery in an adult lung model. Respir Care 2017;62(11):13871395.

18. Ari A, Alwadeai KS, Fink JB. Effects of heat and moisture exchangers and exhaled humidity on aerosol deposition in a simulated ventilatordependent adult lung model. Respir Care 2017;62(5):538-543.

19. Dugernier J, Wittebole X, Roeseler J, Michotte JB, Sottiaux T, Dugernier $\mathrm{T}$, et al. Influence of inspiratory flow pattern and nebulizer position on aerosol delivery with a vibrating-mesh nebulizer during invasive mechanical ventilation: an in vitro analysis. J Aerosol Med Pulm Drug Deliv 2015;28(3):229-236.

20. Pedersen KM, Handlos VN, Heslet L, Kristensen HG. Factors influencing the in vitro deposition of tobramycin aerosol: a comparison of an ultrasonic nebulizer and a high-frequency vibrating mesh nebulizer. J Aerosol Med 2006;19(2):175-183. 


\section{Wet-Side Breath-Enhanced Jet Nebulization}

21. Wan GH, Lin HL, Fink JB, Chen YH, Wang WJ, Chiu YC, et al. In vitro evaluation of aerosol delivery by different nebulization modes in pediatric and adult mechanical ventilators. Respir Care 2014;59 (10): 1494-1500.

22. Palmer LB, Smaldone GC, Simon S, O'Riordan T, Morra L. Tracheal aspirates in long-term mechanically ventilated patients. A human model of gram-negative infection and airway inflammation. Chest 1995; 108(5):1326-1332.

23. Palmer LB, Smaldone GC, Simon SR, O'Riordan TG, Cuccia A. Aerosolized antibiotics in mechanically ventilated patients: delivery and response. Crit Care Med 1998;26(1):31-39.

24. Palmer LB, Smaldone GC. Reduction of bacterial resistance with inhaled antibiotics in the intensive care unit. Am J Respir Crit Care Med 2014;189(10):1225-1233.

25. Rau JL, Ari A, Restrepo RD. Performance comparison of nebulizer designs: constant-output, breath-enhanced, and dosimetric. Respir Care 2004;49(2):174-179.

26. Rau JL. Design principles of liquid nebulization devices currently in use. Resp Care 2002;47(11):1257-1275; discussion 1275-1278.

27. Palmer LB, Smaldone GC, Chen JJ, Baram D, Duan T, Monteforte $\mathrm{M}$, et al. Aerosolized antibiotics and ventilator-associated tracheobronchitis in the intensive care unit. Crit Care Med 2008;36 (7):2008-2013.
28. Luyt CE, Clavel M, Guntupalli K, Johannigman J, Kennedy JI, Wood $\mathrm{C}$, et al. Pharmacokinetics and lung delivery of PDDS-aerosolized amikacin (NKTR-061) in intubated and mechanically ventilated patients with nosocomial pneumonia. Crit Care 2009;13(6):R200.

29. Niederman MS, Chastre J, Corkery K, Fink JB, Luyt CE, Garcia MS. BAY41-6551 achieves bactericidal tracheal aspirate amikacin concentrations in mechanically ventilated patients with Gram-negative pneumonia. Intensive Care Med 2012;38(2):263-271.

30. Montgomery AB, Vallance S, Abuan T, Tservistas M, Davies A. A randomized double-blind placebo-controlled dose-escalation phase 1 study of aerosolized amikacin and fosfomycin delivered via the PARI investigational eFlow inline nebulizer system in mechanically ventilated patients. J Aerosol Med Pulm Drug Deliv 2014;27(6):441-448.

31. Dhand R. Aerosol delivery during mechanical ventilation: from basic techniques to new devices. J Aerosol Med Pulm Drug Deliv 2008;21 (1):45-60

32. Solomita M, Daroowalla F, Leblanc DS, Smaldone GC. Y-piece temperature and humidification during mechanical ventilation. Respir Care 2009;54(4):480-486.

33. Solomita M, Palmer LB, Daroowalla F, Liu J, Miller D, LeBlanc DS, Smaldone GC. Humidification and secretion volume in mechanically ventilated patients. Respir Care 2009;54(10):1329-1335.

This article is approved for Continuing Respiratory Care Education credit. For information and to obtain your CRCE

(free to AARC members) visit

www.rcjournal.com 